\title{
RESEARCH
}

Open Access

\section{Determinants of Acute Asthma Attack among adult asthmatic patients visiting hospitals of Tigray, Ethiopia, 2019: case control study}

Melaku Negash ${ }^{1 *}$, Hagos Tsegabrhan ${ }^{2}$, Teklit Meles $^{3}$, Degena Bahrey Tadesse ${ }^{1}$, Gebreamlak Gidey ${ }^{4}$, Yemane Berhane ${ }^{5}$, Kibrom Berhanu ${ }^{6}$ and Tsgalem Haylemaryam ${ }^{7}$

\begin{abstract}
Introduction: Acute asthma attack is one of the most common causes of visits to hospital emergency departments in all age groups of the population and accounts for the greater part of healthcare burden from the disease. Despite, Acute asthma attack is an important public health problem that affects not only the patients, but also to the family, health professionals, health care institutions and development of the nation, little is known about the risk factors of acute asthma attack.

Therefore, this study is aimed to investigate the determinants of acute asthma attack among.

Objective: The aim of this study was to assess the determinant factors of acute asthma attack among adult asthmatic patients visiting general hospitals of central zone, Tigray, Ethiopia, 2019.

Method: Hospital based unmatched case control study design was conducted in general hospitals of central zone of Tigray, Ethiopia 2019. Data were collected using pretested interviewer administered questionnaire. A total of 289 study subjects ( 96 cases $\& 193$ controls) were selected by systematic random sampling. Data were entered to Epi data version 3.1 then exported to SPSS version 23 for analysis. Bivariate logistic regression was employed to examine the statistical association between dependent and independent variables. Variables with $p$ value $<0.25$ in binary logistic regression were entered to multivariable logistic regression model and variables with $p$ value $<0.05$ was taken as significant determinants of the outcome variable.

Result: A total of 96 adult asthmatic patients who have acute asthma attack (cases) and 193 adult asthmatic patients without attack (controls)) with 100\% response rate were participated in this study. Upper Respiratory tract Infection $[A O R=6.835,95 \% \mathrm{Cl}=3.285,14.222]$, Season $[\mathrm{AOR}=2.204,95 \% \mathrm{Cl}=1.011,4.805]$ kitchen smoke $[\mathrm{AOR}=2.307$, $95 \% \mathrm{Cl} 1.010,5.272] \&$ sleep apnea $[\mathrm{AOR}=9.254,5 \% \mathrm{Cl}=3.563,25.460]$ were significantly associated with acute asthma exacerbation.
\end{abstract}

Keywords: Acute asthma attack, Adult, Determinants, Ethiopia

\footnotetext{
* Correspondence: negashmelaku76@gmail.com

${ }^{1}$ Department of adult health nursing ,school of Nursing, Aksum University, Aksum, Ethiopia

Full list of author information is available at the end of the article
}

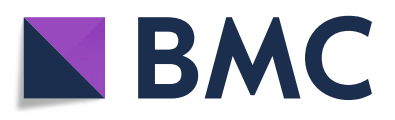

(- The Author(s). 2020 Open Access This article is licensed under a Creative Commons Attribution 4.0 International License, which permits use, sharing, adaptation, distribution and reproduction in any medium or format, as long as you give appropriate credit to the original author(s) and the source, provide a link to the Creative Commons licence, and indicate if changes were made. The images or other third party material in this article are included in the article's Creative Commons licence, unless indicated otherwise in a credit line to the material. If material is not included in the article's Creative Commons licence and your intended use is not permitted by statutory regulation or exceeds the permitted use, you will need to obtain permission directly from the copyright holder. To view a copy of this licence, visit http://creativecommons.org/licenses/by/4.0/. The Creative Commons Public Domain Dedication waiver (http://creativecommons.org/publicdomain/zero/1.0/) applies to the data made available in this article, unless otherwise stated in a credit line to the data. 


\section{Introduction}

Asthma is a long-term inflammatory disease of the respiratory system which is characterized by wheezing, shortness of breath, chest tightness. Globally it affects approximately 300 million people and is estimated to rise to 400 million by 2025 globally [1, 2]. And it is ranked 16th among the leading causes of disability and 28th among the leading causes of burden of disease, as measured by disability adjusted life years (DALYs) [3].

According to Croatian medical journal 2013, an estimate of asthma prevalence in Africa, was 49.7 million in the age of < 15 years $(13.9 \%),<45$ years 102.9 million (13.8\%), and in total population 119.3 million (12.8\%) in 2010 [4].

Asthma exacerbation is defined as a worsening of shortness of breath, cough, wheezing, or chest tightness. If not treated immediately there will be increase in flow resistance causing increased work of breathing, gas exchange inefficiency, respiratory muscle tiredness and finally hypercapnic and hypoxemic respiratory failure [5]. This implies that acute asthma attack is a significant public health problem that affects patients with their parents or families and the community through labor and school loss, frequent emergency clinic visits, a poor quality of life hospitalizations and finally death [6]. According to Centers for Disease Control and prevention (CDC) report, More than 11 million people reported having an acute asthma attack [7].

Despite, in Ethiopia little is known about how risk factors are associated with exacerbation, according to asthma severity and the relative importance of the risk factors. This may be the reason for no policy and strategy to ascertain and acting out of effective intervention in order to reduce the burden of acute asthma attack [8]. Therefore, this study is aimed to full fill this gap.

\section{Methods}

\section{Study setting and study design}

Hospital based unmatched case control study was conducted in the selected general Hospitals of Central zone of Tigray from November 2018 to July 2019.

\section{Study population and sample size determination Source population}

Cases All adult asthmatic patients visited to emergency unit who have acute asthma attack.

Control All adult patients diagnosed as asthma but without acute asthmatic attack who visited the OPD and the regular follow-up unit during the data collection period.

\section{Study population}

Cases All selected adult asthmatic patients visited to emergency unit who have acute asthma attack during the data collection period.

Control All selected adult patients diagnosed as asthma but without acute asthmatic attack who visited the OPD and the regular follow-up unit during the data collection period.

\section{Eligibility criteria \\ Inclusion criteria}

Cases Adult asthmatic patients who have acute asthma attack during the data collection period.

Controls Adult asthmatic patient without acute asthma attack during the data collection period.

\section{Exclusion criteria}

Patients with any history of pulmonary embolism, chronic obstructive pulmonary disease, active pulmonary $\mathrm{TB}$, known congestive heart failure and known mechanical obstruction.

\section{Sample size determination}

Sample size was calculated from Previous study conducted in Uganda [9],using Epi info version 7. sample size was determined based on the assumption of confidence level $=95 \%$; Power $=80 \%$; Odds ratio $=2.132$ with case to control ratio $=1: 2$, proportion of among controls $37.2 \%$, proportion of among cases $=55.8 \%$.

Therefore, the required sample size for cases was $=92$ where as for the controls $=183$ and the overall sample size was $=275$ then after adding $5 \%$ non-response rate, the total sample size was 289. Finally, a sample size for cases was 96 and for controls 193.

\section{Sampling technique and procedure}

The total sample size was allocated to each hospital proportionally based on the number of patients who attend in the selected hospitals. A total number of 585(case 165, control.420) patients attended at the selected Hospitals with in 2 months of the previous year (April 1 to May 30-2018). Systematic random sampling method was applied in each hospital to select 289 participants.

\section{Study Variables \\ Dependent Variable}

Acute asthma attack. 


\section{Independent variables}

Socio-demographic variables Age, Gender, Marital status, Residence, Educational level, Employment status and Occupational status.

Behavioral factors Exercise, vigorous activity Smoking cigarette.

Environmental factors Humidity, Kitchen smoke, dust, Season.

Medical and Clinical characteristics URTI, Sleep apnea, Missing follow-up / appointments,

\section{Operational definitions}

Asthma Those who present with cough, wheezing and difficulty of breathing and diagnosed asthma by physician [10].

\section{Acute Asthma Attack}

Those who present with worsening of wheezing, shortness of breath, cough, chest tightness and diagnosed as acute asthma attack by physician [10].

Smoker:(daily smoker and non-daily smoker) those who currently smokes or those who quit smoking less than 1 year before the assessment [10].

Passive smoker: Smoke inhaled involuntarily by nonsmokers [11].

Nonsmoker: Respondents who report never smoke those who quit smoking greater than 1 year before the assessment.

Vigorous activity: participants doing activity more than 10 min continuously, that increases breathing, like carrying or lifting heavy loads, digging or construction work, cutting fire wood [11].

\section{Data collection tool}

Structured questionnaire was used to collect the data which was adapted from different literatures [9, 12-14]. The questionnaire contains four parts: sociodemographic, environmental factors, behavioral factors, and Medical \&Clinical characteristics.

\section{Data collection procedures}

Data were collected from cases and controls using structured questionnaire and checklists through face-to-face interview and from patients chart review respectively.

Twelve BSc nurses as data collectors and three senior nurse supervisors were recruited for the data collection, Then data from cases were collected after they take all the necessary medical care and they recover from their attack whereas from the controls data were collected after they have completed their assessment by physician and at the last record reviews from their chart. Participants were identified as having upper respiratory tract infection and Obstructive sleep apnea from their medical charts which was diagnosed by senior physicians. This is to mean that, it was just suspected clinically by the time of the acute event. The reason we obeyed to use clinically diagnosis for obstructive sleep apnea is that, there is no accesses of modern diagnostic modality like polysomnography in the study area which was Tigray regional state not only in the study area but also in the country Ethiopia as a whole. The evaluation protocol that we use were a single evaluation visit for each case and even those who have follow-up and developed acute asthma attack were included.

\section{Data quality control techniques}

Data quality was ensured by training of data collectors and supervisors before data collection period. $5 \%$ of the questionnaire was pre-tested in Shire Hospital which was not included in the actual data collection. Based on the findings of the pre-test, questionnaire was modified. The filled questionnaire was checked for completeness and accuracy by data collectors, supervisors and principal investigator each day.. The questionnaire was translated into Tigrigna language for better understanding to both the data collectors and respondents and then back translated into English by another expert to ensure accuracy and consistency.

\section{Data analysis procedures}

Data were entered in to Epi data version 3.1 and analyzed using SPSS version 23.0. The degree of association between independent and dependent variables were assessed using adjusted odds ratio with 95\% confidence interval. Variables $<0.25 p$-value in binary logistic regression were entered to multivariable logistic regression model to control the potential confounding variables. Variables with p-value less than 0.05 in multivariable logistic regression model were taken as significantly associated factors. Variance inflation factor (VIF) was used to assess Multicollinearity between the independent variables. Hosmer and Lemeshow goodness fit model were used to check model fitness.

\section{Ethical consideration}

Ethical clearance was obtained from Mekelle University College of health sciences institutional review board (IRB). A subsequent permission was also obtained from Tigray teaching hospitals. Respondents were informed about the purpose of the study and the interview was conducted after receiving the written consent from participants. Confidentiality of the data/information was secured and was not used for other purposes. 


\section{Results}

Sociodemographic characteristic of study participants Among the participants, $67.7 \%$ (65) of the cases and $60.6 \%$ (117) of the controls were females. The median ages of participants were 43 years with interquartile range (IQR) of 26.5 years among cases and 43 median ages with interquartile range (IQR) of 22 for control.

The educational status, one third 33.3\% (32) of the cases and $24.9 \%$ (48) of the controls were collage and above, where as $14.6 \%$ (14) of the cases and $16.6 \%$ (32) of the controls were unable to read and write. The majority of the cases $63.5 \%$ (61) and $60.1 \%$ (116) of the controls were married (Table 1 ).

\section{Behavioral characteristics of study participants}

Among the participants, $2.1 \%$ (2) of the cases and $1.1 \%$ (6) of the controls were smokers.in parallel with this
$3.1 \%$ of the cases and $4.7 \%$ of the control were passive smokers. Regarding vigorous activity $37.5 \%$ (36) of the cases and $23.8 \%$ (46) of the controls were do vigorous activity. Majority of the participants $72.9 \%$ (70) of the cases and 58\% (112) of the controls were doing exercise.

\section{Medical \& clinical characteristics of study participants}

Among the participants, $44.8 \%$ (43) of the cases and $13.5 \%$ (26) of the controls had Upper Respiratory Tract Infections (URTI) and 29.2\% (28) of the cases and few of the controls 5.2\% (10) had obstructive sleep apnea.

Among the participants, $31.3 \%$ (30) of the cases and $20.7 \%$ (40) of the controls had Missing follow up.

\section{Environmental characteristics of study participants}

Regarding the seasons of a year, spring season (April, May, June) were the season with high percentage $37.7 \%$

Table 1 Sociodemographic characteristics of adult asthmatic patients visiting general hospitals of central zone, Tigray, Ethiopia, 2019

\begin{tabular}{|c|c|c|c|c|}
\hline Variables & & Cases, n (\%) & control n (\%) & Total,n (\%) \\
\hline \multirow[t]{2}{*}{ Sex } & Male & $31(32.3)$ & $76(39.4)$ & $107(37)$ \\
\hline & Female & $65(67.7)$ & $117(60.6)$ & $182(63)$ \\
\hline \multirow[t]{5}{*}{ Age group } & $18-25$ & $12(12.5)$ & $21(10.9)$ & $33(11.4)$ \\
\hline & $26-35$ & $20(20.8)$ & $40(20.7)$ & $60(20.8)$ \\
\hline & $36-45$ & $20(20.8)$ & $43(22.3)$ & $63(21.8)$ \\
\hline & $46-60$ & $28(29.2)$ & 61(31.6) & 89(30.8) \\
\hline & +60 & $16(16.7)$ & $28(14.5)$ & $44(15.2)$ \\
\hline \multirow[t]{2}{*}{ Religion } & Orthodox & 86(89.6) & 174(90.2) & $260(90)$ \\
\hline & Muslim & $10(10.4)$ & 19(9.8) & $29(10)$ \\
\hline \multirow[t]{2}{*}{ Ethnicity } & Tigrian & $90(93.8)$ & 184(95.3) & 274(94.8) \\
\hline & Other & $6(6.2)$ & $9(4.7)$ & $15(5.2)$ \\
\hline \multirow[t]{5}{*}{ Education } & Unable to read \& write & $14(14.6)$ & $32(16.6)$ & $46(15.9)$ \\
\hline & Able to read \& write & $12(12.5)$ & $52(26.9)$ & $64(22.1)$ \\
\hline & Primary school & 15(15.6) & $26(13.5)$ & $41(14.2)$ \\
\hline & Secondary school & $23(24)$ & $35(18.1)$ & $58(20.1)$ \\
\hline & Collage and above & $32(33.3)$ & $48(24.9)$ & $80(27.7)$ \\
\hline \multirow[t]{3}{*}{ Occupational status } & Governmental & $39(40.6)$ & 73(37.8) & 112(38.8) \\
\hline & Self-employed & $35(36.5)$ & 61(31.6) & $96(33.2)$ \\
\hline & Unemployed & $22(22.9)$ & 59(30.6) & $81(28)$ \\
\hline \multirow[t]{4}{*}{ Marital status } & Single & 21(21.9) & $48(24.9)$ & $69(23.9)$ \\
\hline & Married & $61(63.5)$ & $116(60.1)$ & $177(61.2)$ \\
\hline & Divorced & $6(6.3)$ & $14(7.3)$ & 20(69) \\
\hline & Widowed & $8(8.3)$ & $15(7.8)$ & 23(8) \\
\hline \multirow[t]{2}{*}{ Residence } & Urban & 57(59.4) & $121(62.7)$ & 178(61.6) \\
\hline & Rural & $39(40.6)$ & $72(37.3)$ & $111(38.4)$ \\
\hline \multirow[t]{4}{*}{ Income } & $<500$ & 13(13.5) & $38(19.7)$ & $51(17.6)$ \\
\hline & $501-1500$ & $23(24)$ & $45(23.3)$ & $68(23.5)$ \\
\hline & $1501-2500$ & 15(15.6) & $21(10.9)$ & $36(12.5)$ \\
\hline & $>2500$ & $45(46.9)$ & $89(46.1)$ & $134(46.4)$ \\
\hline
\end{tabular}


(109) of acute asthma attack than the autumn season. Majority of the participants $79.5 \%$ (230) were open their window/door while they were cooking. Concerning the kitchen of the participants $32.3 \%$ (31) of the cases and $20.2 \%$ (39) of the control's kitchen have no kitchen smoke (chimney) (Table 2).

\section{Discussion}

Unmatched case control study with 96 cases and 193 controls was conducted to show the determinants of acute asthma attack among adult asthmatic patients visiting general hospitals of central zone, Tigray, Ethiopia.

Having URTI increases the occurrence of acute asthma attack 6.8 times [AOR $=6.835,95 \% \quad \mathrm{CI}=3.285,14.222$ ] than those who have not upper respiratory tract infection (URTI) (Table 3).

This is consistent with the studies conducted in Gondar, Uganda and Ireland $[9,12,15]$.

The association might be due to the mechanism of airway inflammation,mucus hyper secretion, and bronchial hyper responsiveness [16]. In contrast to this study upper respiratory tract infections was no risk factor for acute asthma exacerbation on the study conduct in Pretoria and New Zealand [14, 17]. This difference might be due to difference in health care seeking behavior of the participants in this study.
This study revealed that, sleep apnea was strongly associated with the occurrence of acute asthma exacerbation. Those who have sleep apnea are 9.5 times more likely to run in to acute asthma exacerbation than those who have not sleep apnea $[\mathrm{AOR}=9.524$, $95 \% \mathrm{CI}=3.563,25.460]$.

This findings is comparable with a study done in Gondar and USA [12, 18].

The possible reason is the fact that sleep apnea lead to the worsening of asthma control in patients with concomitant sleep apnea secondary to bronchoconstriction as a result of increase vagal tone while sleeping [19].

The result of this study shows that the odds of having acute asthma in Spring season was 2.2 times higher than the odds of having acute asthma attack in the autumn season $[\mathrm{AOR}=2.204,95 \% \quad \mathrm{CI}=1.011$, 4.805]. This is consistent with a study conducted in Canada in which spring season was triggering factor for asthma exacerbation [20]. Seasonal variation is the risk factors for acute asthma attack especially pollens appearing seasons like spring season exacerbates acute asthma attack. This may be due to the reason that during the spring, tree pollen, mold spores and grass have the power to inflame and narrow the air passages of people who have asthma [21].

Table 2 Environmental characteristics of asthmatic patients visiting general hospitals of central zone, Tigray, Ethiopia, 2019

\begin{tabular}{|c|c|c|c|c|}
\hline Variables & & Cases, n (\%) & control n (\%) & Total, n (\%) \\
\hline \multirow[t]{4}{*}{ Season } & Autumn & $27(28.1)$ & $62(32.1)$ & $89(30.8)$ \\
\hline & Winter & $10(10.4)$ & $28(14.5)$ & $38(13.1)$ \\
\hline & Spring & $48(50)$ & 61(31.6) & 109(37.7) \\
\hline & Summer & $11(11.5)$ & $42(21.8)$ & $53(18.3)$ \\
\hline \multirow[t]{2}{*}{ window /door while cooking } & yes & $76(79.2)$ & $163(84.5)$ & $230(79.5)$ \\
\hline & No & $20(20.8)$ & $30(15.5)$ & $59(20.5)$ \\
\hline \multirow[t]{2}{*}{ Kitchen smoke } & Yes & $65(67.7)$ & 154(79.8) & 219(75.8) \\
\hline & No & $31(32.3)$ & $39(20.2)$ & $70(24.2)$ \\
\hline \multirow[t]{2}{*}{ Exposed to vapor } & Yes & $6.3(6)$ & $11(5.7)$ & $17(5.9)$ \\
\hline & No & $93.7(90)$ & 182(94.3) & 272(94.1) \\
\hline \multirow[t]{2}{*}{ Exposed to gas } & Yes & $23(24)$ & $43(22.3)$ & $66(22.8)$ \\
\hline & No & $73(76)$ & 150(77.7) & $223(77.2)$ \\
\hline \multirow[t]{2}{*}{ Exposed to dust } & Yes & 87(90.6) & 159(82.4) & $246(85.1)$ \\
\hline & No & $9(9.4)$ & $34(17.6)$ & $43(14.9)$ \\
\hline \multirow[t]{2}{*}{ Exposed to fume } & Yes & $40(41.7)$ & $93(48.2)$ & 133(46) \\
\hline & No & $56(58.3)$ & $100(51.8)$ & $156(54)$ \\
\hline \multirow[t]{2}{*}{ Exposed to Humidity } & Yes & 33(34.4) & $64(33.2)$ & 97(33.6) \\
\hline & No & $63(65.6)$ & $129(66.8)$ & $192(66.4)$ \\
\hline \multirow[t]{3}{*}{ Cooking } & Wood & $33(34.4)$ & $66(34.2)$ & $99(34.3)$ \\
\hline & Gas & $8(8.3)$ & $15(7.8)$ & 23(8) \\
\hline & Electric & $55(57.3)$ & $112(58)$ & $167(57.8)$ \\
\hline
\end{tabular}


Table 3 Bivariate and multivariable logistic regression analyses of acute asthma attack among adult asthmatic patients visiting general hospitals of central zone, Tigray, Ethiopia, 2019

\begin{tabular}{|c|c|c|c|c|c|c|}
\hline Variables & & Cases n (\%) & Control n (\%) & Crude OR & Adjusted OR & $\boldsymbol{P}$-value \\
\hline \multirow[t]{5}{*}{ Education Status } & No read\& write & & $14(14.6)$ & $32(16.6)$ & 1 & \\
\hline & read \& write & $12(12.5)$ & $52(26.9)$ & $0.527(0.217,1.282)$ & $0.690(0.214,2.225)$ & 0.535 \\
\hline & Primary school & $15(15.6)$ & $26(13.5)$ & $1.319(0.540,3.222)$ & $0.730(0.213,2.503)$ & 0.617 \\
\hline & Secondary school & $23(24)$ & $35(18.1)$ & $1.502(0.662,3.408)$ & $1.539(0.520,4.558)$ & 0.436 \\
\hline & Collage \& above & $32(33.3)$ & $48(24.9)$ & $1.524(0.705,3.295)$ & $2.181(0.776,6.129)$ & 0.139 \\
\hline \multirow[t]{2}{*}{ Vigorous Activity } & Yes & $36(37.5)$ & $46(23.8)$ & $1.917(1.129,3.256)$ & $1.733(0.825,3.639)$ & 0.147 \\
\hline & No & $60(62.5)$ & 147(76.2) & 1 & 1 & \\
\hline \multirow[t]{2}{*}{ Exercise } & Yes & 70(72.9) & $112(58)$ & $1.947(1.142,3.319)$ & $1.171(0.577,2.377)$ & 0.663 \\
\hline & No & $26(27.1)$ & $81(42)$ & 1 & 1 & \\
\hline \multirow[t]{4}{*}{ Season } & Autumn & $27(28.1)$ & $62(32.1)$ & 1 & 1 & \\
\hline & Winter & $10(10.4)$ & $28(14.5)$ & $0.820(0.350,1.922)$ & $0.900(0.317,2.557)$ & 0.843 \\
\hline & Spring & $48(50)$ & 61(31.6) & $1.807(1.002,3.257)$ & $2.204(1.011,4.805)$ & $0.047^{* *}$ \\
\hline & Summer & $11(11.5)$ & $42(21.8)$ & $0.601(0.269,1.343)$ & $0.599(0.217,1.653)$ & 0.322 \\
\hline \multirow[t]{2}{*}{ Exposed to dust } & Yes & $87(90.6)$ & 159(82.4) & $2.067(0.948,4.509)$ & $2.702(0.923,7.912)$ & 0.070 \\
\hline & No & $9(9.4)$ & $34(17.6)$ & 1 & 1 & \\
\hline \multirow[t]{2}{*}{ Window } & Yes & $76(79.2)$ & 163(84.5) & 1 & 1 & \\
\hline & No & 20(20.8) & $30(15.5)$ & $1.556(0.824,2.935)$ & $1.384(0.573,3.344)$ & 0.470 \\
\hline \multirow[t]{2}{*}{ Kitchen smoke } & Yes & $65(67.7)$ & 154(79.8) & 1 & 1 & \\
\hline & No & $31(32.3)$ & $39(20.2)$ & $1.883(1.083,3.276)$ & $2.307(1.010,5.2725)$ & $0.047^{* *}$ \\
\hline \multirow[t]{2}{*}{ URTI } & Yes & $43(44.8)$ & $26(13,5)$ & $5.211(2.927,9.277$ & $6.835(3.285,14.222)$ & $<.001^{* *}$ \\
\hline & No & $53(55.2)$ & $167(86.5)$ & 1 & 1 & \\
\hline \multirow[t]{2}{*}{ Sleep apnea } & Yes & $28(29.2)$ & $10(5.2)$ & $7.535(3.476,16.337)$ & $9.524(3.563,25.460)$ & $<.001^{* *}$ \\
\hline & No & $68(70.8)$ & 183(94.8) & 1 & & \\
\hline \multirow[t]{2}{*}{ Missing follow up } & Yes & $30(31.3)$ & $40(20.7)$ & $1.739(0.999,3.027)$ & $1.946(0.929,4.075)$ & 0.078 \\
\hline & No & $66(68.8)$ & 153(79.3) & 1 & 1 & \\
\hline
\end{tabular}

Key: * Indicates risk factors for asthma exacerbations in bivariate analysis.

** Indicates factors associated with asthma exacerbation at multivariate analysis

The result of this study was different from a study conducted in Spain which was resulting winter season as higher risk of developing acute asthma attack [22]. The difference could be arisen from seasonal variation between the study areas, due to the influence of temperature and humidity.

In this study, Kitchen smoke (chimney) is highly associated with risk of acute asthma exacerbation.

Those who have no kitchen smoke in their kitchen were 2.3 times at risk to develop acute asthma exacerbation $\quad[\mathrm{AOR}=2.307,95 \% \mathrm{CI}=1.010,5.2725]$ than those who have kitchen smoke. This finding is comparable with the study conducted in India [13]. This is due to the fact that kitchen smoke (chimney) is a way that helps in removing the smokes and fumes from the kitchen and making it clean and smoke free which result in reduction of indoor air pollution and prevents acute asthma exacerbation [23]. Inhaling harmful smoke can inflame lungs and airway, causing them to swell and block oxygen. This can lead to acute asthma exacerbation [24]

\section{Conclusion}

In this study the determinant factors of acute asthma attack were spring season, presence of upper respiratory tract infection (URTI), having no Kitchen smoke in their kitchen and having obstructive sleep apnea.

\section{Limitations}

The diagnosis of respiratory tract infections and sleep apnea was empirical (without laboratory) and all measures used were based on self-reporting, this might end up with social desirability bias. This study may have recall bias, since some of the information was based on the recall of the study participants. Unavailability of studies on acute asthma exacerbation. 


\section{Supplementary information}

Supplementary information accompanies this paper at https://doi.org/10. 1186/s40733-020-00054-w.

Additional file 1. Annex I: English version structured interview questionnaire

\section{Abbreviations}

AAA: Acute Asthma Attack; AOR: Adjusted Odds Ratio; Cl: Confidence Interval; COR: Crude Odds Ratio; CSA: Central Statistical Agency; IQR: Interquartile Range; NHIS: National Health Interview Survey; OPD: Out Patient Department; TRHDA: Tigray Region Health Development Agency; URTI: Upper Respiratory Tract Infection; VIF: Variance Inflation Factor

\section{Acknowledgments}

Authors thanks to public general hospitals of central zone Tigray, Ethiopia for their co-operation, to data collectors, supervisors, for the health staffs of the hospitals and to the study participants for their valuable information.

\section{Author's contributions}

MN: was made substantially contributions to conceived and designed the study, analysis the data, methodology, data interpretation and wrote the final manuscript.TM, DB, GG,YB, had equally contributed to analysis and interpretation of the data. Whereas HT, TH and KB substantial contribution in reviewing overall the study in analysis, interpretation of data, have drafted the manuscript and substantively revised the work. All authors read and approved the final manuscript.

\section{Funding}

Not applicable.

\section{Availability of data and materials}

The datasets used and analyzed during the current study are presented within the manuscript and available from the corresponding author on reasonable request.

\section{Ethics approval and consent to participate}

Ethical clearance was obtained from Mekelle University College of health sciences institutional review board (IRB). Official supportive letters were obtained from Regional Health Bureau (TRHB) and central zone health office. Respondents were informed about the purpose of the study and the interview was conducted after receiving the written consent from participants. The right of participants to withdraw from the study at any time, without any precondition were secured and participants were informed. Confidentiality of the data/information was secured and was not used for other purposes. No personal identifiers was used on the questionnaire. To maintain confidentiality, data collector was recruited from the study unit.

\section{Consent for publication}

Not applicable.

\section{Competing interests}

The authors declare that they have no competing interests.

\section{Author details}

${ }^{1}$ Department of adult health nursing ,school of Nursing, Aksum University, Aksum, Ethiopia. ${ }^{2}$ Department of Psychiatric, Mekelle University, Mekelle, Ethiopia. ${ }^{3}$ Adwa General Hospital, Adwa, Ethiopia. ${ }^{4}$ Department of midwifery, Aksum University, Aksum, Ethiopia. ${ }^{5}$ college of medicine and health science, Adigrat university, Adigrat, Ethiopia. ${ }^{6}$ Maternity and reproductive health nursing, Mekelle University, Mekelle, Ethiopia. ${ }^{7}$ Department of Emergency and critical care nursing, Mekelle University, Mekelle, Ethiopia.
Received: 7 December 2019 Accepted: 17 March 2020

Published online: 03 April 2020

\section{References}

1. Adams, JY., Sutter, M.E. \& Albertson, T.E. The Patient with Asthma in the Emergency Department. Clinic Rev Alleg Immunol 43, 14-29 (2012). https:// doi.org/10.1007/s12016-011-8273-z.

2. Shah R, Saltoun CA. Chapter 14: Acute severe asthma (status asthmaticus) Allergy and Asthma Proceedings, 2012; 33(Supplement 1):S47-S50. Acute severe asthma. InAllergy and Asthma proceedings 2012 (Vol. 33, No. 3, p. 47). OceanSide Publications.

3. The Global Asthma Report 2018. Auckland, New Zealand: Global Asthma Network, 2018.

4. Adeloye D, Chan KY, Rudan I, Campbell H. An estimate of asthma prevalence in Africa: a systematic analysis. Croat Med J. 2013:54(6):519-31.

5. Park HW, Tantisira KG. Genetic signatures of asthma exacerbation. Allergy, Asthma Immunol Res. 2017:9(3):191-9.

6. Stewart WF, Ricci JA, Chee E, Morganstein D. Lost productive work time costs from health conditions in the United States: results from the American Productivity Audit. J Occup Environ Med. 2003;45(12):1234-46.

7. CDC,National Health Interview Survey (NHIS) 2014

8. Jackson DJ, Sykes A, Mallia P, Johnston SL. Asthma exacerbations: Origin, effect and prevention. J Allergy Clin Immunol. 2011;128:1165-74.

9. Sanya RE, Kirenga BJ, Worodria W, Okot-Nwang M. Risk factors for asthma exacerbation in patients presenting to an emergency unit of a national referral hospital in Kampala, Uganda. Afr Health Sci. 2014;14(3):707-15.

10. Riley L, Gouda H, Cowan M. Noncommunicable Diseases Progress Monitor, 2017: World Health Organization; 2017.

11. Ethiopia steps report on risk factors for Chronic Non Communicable Diseases and prevalence of selected NCDs. Ethiopia public Health institute. 2016

12. Belachew SA, Erku DA, Yimenu DK, Gebresillassie BM. Assessment of predictors for acute asthma attack in asthmatic patients visiting an Ethiopian hospital: are the potential factors still a threat? Asthma Res Pract. 2018:4(1):8.

13. Sharma GL, Choudhary GS. Assessment of Risk Factors for Acute Asthma Attack in Asthmatic Patients: A Hospital Based Study. Int Arch BioMed Clin Res. 2018;4(4):46-8.

14. Geyser M, Rheeder P. Risk factors precipitating exacerbations in adult asthma patients presenting at Kalafong Hospital, Pretoria. S Afr Fam Pract. 2008;50(4):67-e

15. Nicholson KG, Kent J, Ireland DC. Respiratory viruses and exacerbations of asthma in adults. BMJ. 2003;307(6910):982-6.

16. Fraenkel DJ, Bardin PG, Sanderson G, et al. Lower airways inflammation during rhinovirus colds in normal and in asthmatic subjects. Am J Respir Crit Care Med. 2009;151(3):879-86.

17. Kolbe J, Fergusson W, Vamos M, Garrett J. Case-control study of severe lifethreatening asthma (SLTA) in adults. Thorax. 2002;57(4):317-22.

18. De-Lei K, Zheng Q, Hui S, Hong Y. Association of Obstructive Sleep Apnea with Asthma exacerbation; 2017

19. Alkhalil M, Schulman E, Getsy J. Obstructive sleep apnea syndrome and asthma: what are the links? J Clin Sleep Med. 2009;5(01):71-8.

20. Tarlo S, Broder I, Corey P, et al. A case-control study of the role of cold symptoms and other historical triggering factors in asthma exacerbations. Can Respir J. 2000;7(1):42-8.

21. Surrena $H$, editor. Handbook for Brunner and Suddarth's textbook of medical-surgical nursing. Lippincott Williams \& Wilkins; 2010.

22. Pola-Bibian B, et al. Asthma exacerbations in a tertiary hospital: clinical features, triggers, and risk factors for hospitalization. J Investig Allergol Clin Immunol. 2016:0. https://doi.org/10.18176/jiaci.0128.

23. Eisner $\mathrm{M}$, et al. Exposure to indoor combustion and adult asthma outcomes: environmental tobacco smoke, gas stoves, and woodsmoke. Thorax. 2002; 57(11):973-8.

24. Smeltzer SC, Bare BG, Hinkele JL, Cheever KH. Brunner and Suddath's Text Book of Medical Surgical 2010. Wolters Kluwer Health:Lippincott Williams \& Wilkins. Nursing, vol. 1. 12th ed. p. 622.

\section{Publisher's Note}

Springer Nature remains neutral with regard to jurisdictional claims in published maps and institutional affiliations. 